\title{
Os Saberes Docentes dos Professores da Educação Infantil: A Prática Pedagógica entre o Educar e o Cuidar
}

\author{
Jessica Alves Landim ${ }^{1}$; Marta Callou Barros Coutinho ${ }^{2}$; Maria do Socorro Cecílio Sobral ${ }^{3}$
}

\begin{abstract}
Resumo: A Educação Infantil exige do professor, não só formação na área, que ele possa dispor de diversos saberes que contribuirão para uma boa atuação em sala de aula. O objetivo do estudo em questão foi identificar os saberes necessários à atuação dos professores da educação infantil. Estudo qualitativo, que contou com entrevista semiestruturada com três educadores da área, dentro do contexto empírico de uma escola do município de Salgueiro-PE. As respostas foram agrupadas em categorias, a saber: 1) As trajetórias e os percursos dos professores da educação infantil; 2) Saberes Docentes que emergem na prática pedagógica da Educação Infantil os resultados levaram a crer que, é necessário repensar em uma prática pedagógica dada por diferentes saberes que atendam com precisão as necessidades das crianças. Espera-se com os resultados desta investigação contribuir para uma prática educativa de qualidade para os professores da Educação Infantil, quanto ao seu fazer pedagógico.
\end{abstract}

Palavras-Chave: Educação Infantil. Prática Pedagógica. Saberes docentes.

\section{The Teaching Knowledge of Teachers of Child Education: The Pedagogical Practice between Educating and Caring}

\begin{abstract}
Early childhood education demands from the teacher, not only training in the area, that it can have different knowledge that will contribute to a good performance in the classroom. The objective of the study in question was to identify the knowledge necessary for the performance of the teachers of early childhood education. A qualitative study, which had a semi-structured interview with three educators in the area, within the empirical context of a school in the municipality of Salgueiro, State of Pernambuco. The answers were grouped into categories, namely: 1) The trajectories and paths of pre-school teachers; 2) Knowing Teachers that emerge in the pedagogical practice of Early Childhood Education, the results have led us to believe that it is necessary to rethink in a pedagogical practice given by different knowledges that precisely meet the needs of children. It is hoped that the results of this research contribute to a quality educational practice for the teachers of Early Childhood Education, regarding their pedagogical practice.
\end{abstract}

Keywords: Early Childhood Education. Pedagogical Practice. Teacher's knowledge.

\section{Introdução}

Pensar os saberes docentes de professores da educação infantil requer esforço e reflexão. A escolha do tema, surgiu do interesse em compreender como os professores da Educação

\footnotetext{
${ }^{1}$ Faculdade de Ciências Humanas do Sertão Central (FACHUSC). jessicaenqt@ @otmail.com;

${ }^{2}$ Faculdade de Ciências Humanas do Sertão Central (FACHUSC). mcallou@ hotmail.com;

${ }^{3}$ Faculdade de Ciências Humanas do Sertão Central (FACHUSC). socorrosobral@bol.com.br.
} 
Infantil utilizam e constroem saberes para atender as necessidades do contexto da sala de aula entre o educar e o cuidar. A partir de conversas com os professores da área da educação infantil, percebeu-se que muitos educadores sentem dificuldades em desenvolver práticas que atendam as necessidades dos alunos, causando com isto a desmotivação, a falta de limites e dificuldades de aprendizagem.

Embora sejam feitos esses relatos, observa-se também que há uma falta de diálogo entre os pares na instituição escolar na construção de estratégias de ensino adequadas que os atenda nas suas dificuldades. A reflexão sobre o fazer pedagógico é ação para reconstrução de uma prática pedagógica que atenda todo o alunado.

Nessa perspectiva, Lacerda e Mak (2015) ao realizarem pesquisa referente à prática pedagógica do professor de educação infantil concluíram que esta, se desenvolve por meio de diferentes saberes que envolvem conhecimentos provenientes da sua experiência, de conhecimentos específicos sobre o currículo, sobre a educação e sobre a ação pedagógica. Este estudo revelou, ainda, que a prática pedagógica dos professores da educação infantil apresenta relações muitas vezes simplistas e reducionistas. Entretanto, também foi possível verificar que é possível relacionar a atividade docente com o processo educativo em seu sentido mais amplo. O educador deve modificar seus procedimentos de ensino, colocando em pauta do seu trabalho atividades motivadoras e significativas ao desenvolvimento integral das crianças.

Pietrobon (2007) também analisou saberes docentes dos professores da educação infantil e concluiu que o trabalho pedagógico nessa fase requer o desenvolvimento de atividades que englobem o educar e o cuidar. Nesse sentido, há uma variedade de saberes que os professores necessitam articular em suas práticas, considerando a fase de desenvolvimento e a livre-expressão das crianças, como também as diversas linguagens: oral e escrita, matemática, artística, corporal, musical, temporal e espacial. Compreende-se assim que para a prática de aprendizagens significativas o professor precisa dar condições às crianças para que possam desenvolver suas múltiplas criatividades e capacidades intelectuais de forma livre, sem nenhum tipo de repressão.

Sobral e Lopes (2011) após investigarem sobre os saberes docentes na educação infantil perceberam avanços no que se refere à (re) significação de tais saberes por parte dos sujeitos da pesquisa, configurando rupturas importantes com suas concepções iniciais. Apontaram para a necessidade de um trabalho de formação permanente, no contexto da instituição, de modo a propiciar o diálogo entre as práticas pedagógicas e as propostas curriculares. A formação permanente, nesse sentido, torna-se essencial para a construção de novos saberes, as instituições 
deveram adotar políticas públicas bem definidas para essa formação.

Os saberes docentes segundo Tardif (2005) são temporais e construídos nas trajetórias vividas pelos professores. Os professores desenvolvem esses saberes a partir da experiência vivida e pela troca de saberes com seus pares no contexto pessoal e/ou profissional. Acreditase, portanto, que os professores em suas trajetórias experienciais constroem a base que lhe proporcionam estoque de estratégias de ensino para utilizarem no decorrer da sua prática pedagógica. Essa reflexão leva-se ao seguinte questionamento: como os docentes da educação infantil desenvolvem saberes na prática pedagógica para o “educar e o cuidar”?

Com o interesse em melhor compreender como os professores da Educação infantil foram construindo saberes na sua trajetória docente para atuar na prática pedagógica, questionase: como se dá o desenvolvimento da interação, a autonomia e formação de valores na Educação Infantil?

Diante desse questionamento surge o objetivo da pesquisa: identificar os saberes necessários à atuação de professores de educação infantil, bem como a investigação das trajetórias e dos percursos e os saberes docentes dos professores da desta modalidade.

\section{Saberes docentes}

O professor é um profissional que possui múltiplos saberes em sua atuação docente, saberes esses que estão relacionados com a identidade, experiência de vida, sua história como professor e a relação com alunos e também com os demais que atuam na escola e na medida em que se constrói essa prática, vai surgindo outros conhecimentos, outras experiências, que se unem e se transformam em novos saberes docentes. Pesquisador afirma:

[...] A ideia de base é que esses saberes (esquemas, regras, hábitos, procedimentos, tipos, categorias, etc.) não são inatos, mas produzidos pela socialização, isto é,através do processo de imersão dos indivíduos nos diversos mundos socializados, [...] nos quais eles constroem, em interação com os outros, sua identidade pessoal e social. (TARDIF, 2002, p. 71)

O autor considera o saber docente como sendo um saber plural, ou seja, ele se constrói através de vários fatores, não são saberes parados aprendidos em uma formação inicial e se repetem durante todo trajetória docente. São saberes sempre em movimento que se misturam com os saberes de outros profissionais e se refazem incessantemente.

Ele destaca a existência de quatro tipos diferentes de saberes que envolvem a vida docente: os saberes da formação profissional que são os saberes aprendidos em instituições de 
formação de professores (formação inicial) e também se apresentam nos cursos de formação continuada; os saberes disciplinares são aqueles procedentes das diferentes áreas de conhecimento; os saberes curriculares que dizem respeito às metas, conteúdos e métodos dos quais são classificados pelas instituições escolares como saberes sociais. Esses já se encontram determinados em sua forma e conteúdo, frutos provenientes da tradição cultural e dos grupos que produzem os saberes sociais ligados à ação docente através de tudo que deve ser transmitido (disciplinas, programas escolares e matérias); os saberes experienciais que são adquiridos a partir da prática docente.

Sendo assim, o educador precisa ter a capacidade de integrar, dominar, e movimentar tais saberes enquanto condição para a prática educativa, mas essa autonomia só será consolidada, através de pesquisa e da produção de conhecimentos. É preciso descartar a ideia de ser mero transmissor e passar a ser produtor do conhecimento, uma vez que se atualizar pedagogicamente é ação tão importante.

Os saberes docentes são mobilizados e aplicados na prática pedagógica, estes serviram para solucionar os problemas desses profissionais em exercício e dando sentido às situações de trabalho próprias dos mesmos.

\section{A Prática Pedagógica na Educação Infantil}

A prática pedagógica na educação infantil demanda cuidado e atenção, visto que não se pode esquecer-se dos principais envolvidos: As crianças, que são seres em desenvolvimento, com capacidades de dialogar, de expressar pensamentos e seu desejos, indispensáveis à vida e fundamentais para a construção pessoal. Assim se faz necessário uma boa atuação do fazer docente a qual deve favorecer seu o desenvolvimento das mesmas.

O professor que atua na Educação infantil precisa estar informado do desenvolvimento físico e intelectual das crianças e das técnicas que possam auxiliar no desenvolvimento do seu processo ensino aprendizagem de forma a atender suas inúmeras necessidades em todos os seus níveis de aprendizagem.

O Ministério da Educação em 1998 lançou o Referencial Curricular Nacional para a Educação Infantil - RCNEI, que tem como principal objetivo nortear o professor na trajetória da Educação Infantil, visto que esta é fundamental para a formação social da criança, o documento organiza os níveis de aprendizagem por idades de zero a três anos e quatro a cinco anos. De acordo com este documento fica esclarecido que: 
Considerando-se as particularidades da faixa etária compreendida entre zero e cinco anos e suas formas específicas de aprender, criou-se categorias curriculares para organizar os conteúdos a serem trabalhados nas instituições de educação infantil. Esta organização visa a abranger diversos e múltiplos espaços de elaboração de conhecimentos e de diferentes linguagens, a construção da identidade, os processos de socialização e o desenvolvimento da autonomia das crianças que propiciam, por sua vez, as aprendizagens consideradas essenciais. (BRASIL, 1998, p. 45)

Essa forma de organizar os conteúdos de acordo com faixa etária é de grande valia para o desenvolvimento das crianças, uma vez que apresentam natureza singular, as quais se caracterizam como seres que sentem e pensam o mundo de um jeito muito próprio.

Brasil (1998) estabelece dois âmbitos de experiências para serem trabalhadas durante a prática do Ensino Infantil: Formação Pessoal e Social, e Conhecimento de Mundo, os quais são formados pelos seguintes eixos de trabalho: Identidade e autonomia, Movimento, Artes visuais, Música, Linguagem oral e escrita, Natureza e sociedade e, Matemática.

Todo o trabalho proposto pelo docente da educação infantil deve estar direcionado para a socialização do aluno, o desenvolvimento das capacidades motoras e da fala, à inserção ao mundo da literatura e do faz de conta e às diversas trocas de experiências dentro e fora da sala de aula, do desenvolvimento das novas formações psicológicas, enfim, educando-as na sua totalidade. Educar a criança na sua totalidade é garantir a ela todos os seus direitos de cidadã. Assim, é necessário dispor de um planejamento pedagógico de qualidade que permita o aprimoramento das funções psicológicas superiores.

De acordo de Chaves, Lima e Girotto (2012, p. 39) “[...] para que os procedimentos didáticos sejam ricos de significado, a comunicação, a afetividade e a escolha de recursos e procedimentos devem figurar como características essenciais no processo de ensino". Compreende-se assim que as atividades desenvolvidas no espaço da educação infantil devem ser imersas de sistematização e que garanta oportunidades de participação e o acesso amplo à cultura proporcionadora de uma educação de qualidade.

Mello (2012) posiciona-se dizendo que:

Nós, adultos, somos importantes na organização do espaço, na proposição de
atividades significativas, na coordenação das atividades que propomos, nas diferentes
formas de ajuda que as crianças solicitam, na ampliação daquilo que as crianças
fazem; mas a criança precisa realizar, ela própria, as atividades. [...] Por isso, o
processo de ensinar e de aprender é sempre colaborativo, ou seja, resulta de nossa
ação conjunta com a criança (MELLO, 2012, p. 22)

Diante desta afirmação, enfatiza-se a importância da mediação do educador com a sistematização do planejamento adequada às crianças. $\mathrm{O}$ educador sendo um ser mais 
experiente como é deve permitir a aproximação das crianças com o saber acumulado da história da humanidade, como também possibilitar uma relação de diálogo que incentive o seu interesse pelos diferentes tipos de conhecimentos, de forma que o leve a aprender. Tudo isto será possível se ocorrer a proposição de experiências positivas, diferenciadas e estimuladoras de atividades que desenvolvam as aprendizagens de variadas funções psicológicas superiores das crianças.

\section{O Educar e o Cuidar na Educação Infantil}

Ao longo da história do atendimento ás crianças pequenas em instituições escolares, percebe-se diferenças na sua finalidade inicial, tendo em vista que a maioria delas, no caso das creches, foi criada com o objetivo de atender crianças de baixa renda, tinham caráter assistencialista, ou seja, era voltada para o Cuidar, á questão da higiene e da saúde devido ao um número muito grande de mortalidade infantil. Enquanto a Pré-escola era destinada a crianças de renda média com a finalidade de dar auxílio pedagógico, isto é, educar.

Atualmente esse conceito mudou e agora se sabe que o objetivo da educação infantil não se resume em cuidar, nem somente em educar, mas sim em educar e cuidar.

Brasil (1998) enfatiza que:

Educar significa, portanto, propiciar situações de cuidados, brincadeiras e aprendizagem orientadas de forma integrada e que possam contribuir para o desenvolvimento das capacidades infantis de relação interpessoal, de ser e estar com outros, em uma atitude básica de aceitação, respeito e confiança, e o acesso, pelas crianças, aos conhecimentos mais amplos da realidade social e cultural. (BRASIL, 1998 p.23)

Assim o educar permite que o aluno se desenvolva em diversas formas, com base em suas necessidades.

E o cuidar está voltado segundo Brasil (1998),

[...] cuidados relacionais, que envolvem a dimensão afetiva e dos cuidados com os aspectos biológicos do corpo, como a qualidade da alimentação e dos cuidados com a saúde, quanto da forma como esses cuidados são oferecidos e das oportunidades de acesso a conhecimentos variados aos cuidados básicos, a alimentação, higiene, mas de uma forma integrada ao educar (BRASIL, 1998, p.24).

Entende-se aqui, que o cuidado é aquele que se refere à proteção, a saúde e a alimentação, a afetividade, interação, e ao estímulo.

Nos dias atuais a educação infantil não possui mais um caráter assistencialista como era antigamente, mas ela é também ação educativa. O Educar e o Cuidar são indissociáveis, pois 
contribuem para o desenvolvimento global da criança em todos os aspectos físico, intelectual, afetivo e social.

Sabe-se da importância da função pedagógica, no processo educativo e social nesta fase da criança, mas ainda existem pessoas que infelizmente possuem uma visão errônea e ultrapassada sobre o profissional da Educação Infantil, visto que o jugam como alguém que apenas cuida da criança. Esse trabalho exige do profissional muito estudo teórico e prático nas atividades realizadas com esse público, dado a importância dessa fase da educação básica, pois são nos primeiros anos de vida que acontece a construção da personalidade e do conhecimento. Todos os estímulos oferecidos a elas, seja motor, afetivo ou social, são primordiais para uma vida harmoniosa e feliz.

A importância para o desenvolvimento da criança deve começar a ser dada desde seu nascimento. Pois em seus primeiros meses de vida expressa sinais de interação com o ambiente em que vive, seja através de um choro por não gostar de ficar sozinho, um sorriso ou de estender os braços pedindo colo. Tudo isso faz parte do seu desenvolvimento, mas deve ser levado em conta o estímulo dado a ela para garantir esse desenvolvimento.

Por isso é importante que o professor da educação infantil saiba como agir para assegurar um crescimento saudável e enriquecedor às crianças.

\section{Percurso Metodológico}

A Metodologia aplicada buscou fornecer os instrumentos necessários para a realização de uma pesquisa qualitativa, que segundo Demo (1998) "dedica-se mais a aspectos qualitativos da realidade, ou seja, olha prioritariamente para eles, sem desprezar os aspectos também quantitativos. "Entende-se assim, que a pesquisa qualitativa tem como intuito obter dados voltados para compreensão de atitudes e comportamentos de algum grupo de pessoas, objetivando entender o problema e o ponto de vista de determinado grupo em questão.

Fez-se uso de um estudo de caso em uma escola pública da cidade de Salgueiro-PE. A coleta de dados foi feita por meio da realização de entrevista semiestruturada com três professores da escola vinculada à educação infantil.

Considerando que o objeto da presente investigação é explorar os saberes docentes elaborados pelos professores da Educação Infantil, buscando as possibilidades e movimentos envolvidos não como algo definitivo, mas sim em constante processo de construção profissional e social. 


\section{A seleção do campo de pesquisa}

A investigação ocorreu na Escola Monteiro Lobato (nome fictício), que pertence a Secretaria de Educação do município de Salgueiro PE, nessa escola há quatro professores na Educação Infantil. A escolha se deu nessa instituição, sobretudo devido a maior possibilidade de acesso aos docentes que trabalham nela e pelo reconhecimento e qualidade e referências de ensino de Educação Infantil.

\section{Sujeitos investigados: perfis dos professores}

Para realização da pesquisa, enviou-se uma carta a três professores da área da Escola acima citada convidando-os a participarem de uma entrevista dos quais aceitaram. Estes foram selecionados devido à realização das suas práticas pedagógicas consideradas, bem sucedidas na instituição. Para preservar a identidade dos professores entrevistados, cada um recebeu a sigla "P" e um número de 1 a 3 para identificação dos mesmos.

O primeiro entrevistado foi $\mathrm{P} 1$, graduado em Pedagogia, pós-graduação em Psicopedagogia clínica e institucional, com8 anos de experiência na educação infantil. A segunda entrevistada foi P2, graduado em Pedagogia, pós-graduação em psicopedagogia possui 10 anos atuação na educação infantil. A terceira entrevistada foi P3, graduado em Pedagogia, pós-graduação em Psicopedagogia, há 15 anos atua na educação infantil.

\section{Resultados e Discussões}

\section{As trajetórias e os percursos dos professores da educação infantil}

Com base na análise dos dados, verificou-se que algumas professoras consideram que a família teve muita influência na escolha da profissão. A entrevistada P1 menciona o apoio que recebeu da mãe para atuar como professora "A minha mãe sempre foi professora, então essa profissão sempre esteve próxima a mim, por isso eu também quis entrar nessa carreira docente" (P1).

Da mesma forma, a professora P2, também evidencia a interferência da família para sua escolha, "Essa escolha já é quase uma herança de família, pois, minha avó foi professora, minha mãe e agora eu, sempre me identifiquei nessa área desde criança.” (P2). 
Assim como a família o contato do aluno com a instituição de ensino também pode servir de motivação para a busca dessa profissão. À vista disso, influenciada por professoras desde os anos iniciais da escolarização, P3 ressaltou que "Ser professor sempre foi meu desejo, desde que inicie meus estudos observava meus professores, a forma como ensinavam e sua dedicação e comprometimento para com seus alunos" (P3).

Ficou claro que ao frequentarem as escolas ou dentro da própria família, os professores constroem modelos a respeito dessa profissão. Suas referências sobre essa docência são adquiridas em diferentes fontes. Estas se classificam em: Saberes pessoais dos professores que são os saberes adquiridos na família, no ambiente de vida, na educação no sentido amplo, elas se integram no trabalho docente através da história de vida e pela socialização primária. Já os adquiridos na escola primária e secundária, são chamados de Saberes provenientes da formação escolar anterior, que fundamenta sua prática envolvendo seu trajeto pré-profissional, decorrida da própria história de vida enquanto alunos (TARDIF, 2002).

A partir dessa afirmação compreendeu-se que o contato de antigos alunos (atuais professores) nas instituições de ensino, também serve de exemplo, para exercer tal função.

\section{Saberes Docentes que emergem na prática pedagógica da Educação Infantil}

No que se refere aos Saberes Docentes da Educação Infantil, as professoras entrevistadas afirmaram que mobilizam diversos saberes para a realização da docência.P3 deixou claro que "um bom docente precisa ser estudioso, crítico, reflexivo e ativo também, não bastam os saberes específicos das áreas do conhecimento, mas também os saberes construídos a partir de reflexão de práticas durante sua trajetória”.

Foi perceptível, à partir dessa afirmativa que o professor da Educação Infantil necessita ser polivalente assim como afirma Brasil (1998):

$\mathrm{O}$ trabalho direto com crianças pequenas exige que o professor tenha uma competência polivalente. Ser polivalente significa que ao professor cabe trabalhar com conteúdos de naturezas diversas que abrangem desde cuidados básicos essenciais até conhecimentos específicos provenientes das diversas áreas do conhecimento. (BRASIL, 1998 p. 41)

Notou-se na referida entrevista que a afetividade tem seu lugar garantido em sala de aula de acordo com as entrevistadas "Ao lecionar, professor de Educação Infantil deve articular diversos saberes, saber escutar, saber ser carinhosa, saber entender a realidade de cada aluno, ser criativo em sua prática”(P1),P2também apontou que a "relação entre professor e aluno 
também formam os saberes docentes e esta transmissão do conhecimento deve ser pautada na confiança, afetividade e respeito mútuo".

Atentado a esses pensamentos Brasil (1998) afirma que:

\begin{abstract}
Adultos amigáveis, que escutam as necessidades das crianças e, com afeto, atendem a elas, constituem-se em um primeiro passo para criar um bom clima. As crianças precisam ser respeitadas em suas diferenças individuais, ajudadas em seus conflitos por adultos que sabem sobre seu comportamento, entendem suas frustrações, possibilitando-lhes limites claros. (BRASIL, 1998 p. 67).
\end{abstract}

As escolas têm recebido cada vez mais crianças carentes de afeto. As famílias que é a base inicial formadora desse valor, na maioria das vezes se negam a esta prática, colocando todo esse fazer aos cuidados da escola, especificamente aos cuidados do professor. Daí surge a indisciplina, a desmotivação, a violência e a falta da aprendizagem. Assim, é preciso que seja estabelecido vínculos afetivos entre o professor e a criança na Educação Infantil para que o processo de aprendizagem seja de fato consolidado.

\title{
Considerações Finais
}

Este estudo permitiu analisar os saberes considerados como necessários ao professor de Educação Infantil na concepção dos autores citados, tendo como marco principal a certeza de que a construção dos saberes e a constituição do ser não ocorrem em momentos nem de maneira compartimentada, mas de forma integral e que por isto o trabalho voltado para o educar e cuidar devem ser dados pela prática de atividades baseadas em concepções que respeitem a diversidade, o momento e a realidade peculiares à infância, não deixando que estas corram o risco de se transformar ações rotineiras e mecanizadas, guiadas por regras.

As atitudes e os procedimentos a serem praticados precisam estar baseados nos conhecimentos específicos do desenvolvimento biológico, emocional, e intelectual das crianças, nas diferentes realidades socioculturais de cada uma.

O educador da educação infantil não deve ser visto como substituto da família, mas como ser que cuida e que possibilita a educação integral das crianças que ali se encontram.

$\mathrm{O}$ ato de cuidar e educar estar fundamentado ao ofício e a excelência do verdadeiro educador, pois cuidar de uma criança é também educá-la. Agindo assim, está verdadeiramente garantido o desenvolvimento integral desse ser. Para isso é preciso dispor de experiências e competências pedagógicas, capazes de entender as necessidades e interesses das crianças em cada momento e a realidade vivida por elas. 
Compreendeu-se que o professor é um mediador de novas conquistas e precisa sempre oferecer diversas possibilidades educacionais para que a criança descubra suas potencialidades.

Dessa forma, não basta apenas ter conhecimento de materiais e técnicas a serem aplicadas no fazer pedagógico, mas ter sensibilidade, elucidação, produzir motivação, ajudar a criança a encontrar o caminho de descobertas e compreensão do mundo para que ela possa construir sua própria identidade e se humanizar de maneira lúdica, colorida e educativa.

O Trabalho com crianças da educação infantil exige dos profissionais desta área estudos teóricos e práticas adequadas à formação e construção da personalidade e do conhecimento históricos social de cada um.

\section{Referências}

BRASIL. Referencial Curricular Nacional para a Educação Infantil. Ministério da Educação e do Desporto, Secretaria de Educação Fundamental. Brasília, MEC/SEF, 1998.

CHAVES, M.; LIMA, E. A. de; GIROTTO, C. G. G. S. Intervenções pedagógicas e realizações humanizadoras com professores e crianças. In: CHAVES, M. (Org.). Intervenções pedagógicas e educação infantil. Maringá: EDUEM, 2012, p. 37-49.

DEMO, Pedro. Pesquisa qualitativa. Busca de equilíbrio entre forma e conteúdo. Rev.latinoam.enfermagem, Ribeirão Preto, v. 6, n. 2, p. 89-104, abril 1998.

LACERDA, Lilian dos Santos; MAK, Denise. Saberes Docentes Na Educação Infantil. In: EDUCERE, XII. 2015. 1. ed. Anais... Curitiba, 2015. p. 38628-8638 . Disponível em: <http://educere.bruc.com.br/arquivo/pdf2015/16804_10805.pdf>. Acesso em: 24 set. 2018.

MELLO, S. A. Uma teoria para orientar o pensar e o agir docente: o enfoque histórico-cultural na prática de educação infantil. In: CHAVES, M. (Org.). Intervenções pedagógicas e educação infantil. Maringá: EDUEM, 2012, p. 19-35.

PIETROBON, S. R. G. Os saberes de professores da Educação Infantil: as diversas linguagens. In: 16o. Congresso de Leitura do Brasil, 2007, Campinas. Anais do 16o. COLE, 2007. v. 1.

SOBRAL, Elaine Luciana Silva. ; LOPES, Denise Maria de Carvalho. Educação Infantil, currículo e saberes docentes: percursos de uma pesquisa-ação. Revista espaço do currículo, v. 3, p. 626-641, 2010.

TARDIF, Maurice. Saberes docentes e formação profissional. Petrópolis, RJ: Vozes, 2002.

\section{Como citar este artigo (Formato ABNT):}

LANDIM, Jessica Alves; COUTINHO, Marta Callou Barros; SOBRAL, Maria do Socorro Cecílio. Os Saberes Docentes dos Professores da Educação Infantil: A Prática Pedagógica entre o Educar e o Cuidar. Id on Line Rev.Mult. Psic., 2019, vol.13, n.43, p. 128-138. ISSN: 1981-1179. 